\title{
Eine objektiv-rechtliche Gewährleistung der Rundfunkfreiheit in der Europäischen Union?
}

Nationales Rundfunkverfassungsrecht und unionsrechtlicher Grundrechtsschutz im Spiegel divergierender Tradition, Funktion und Konzeption der Grundrechte

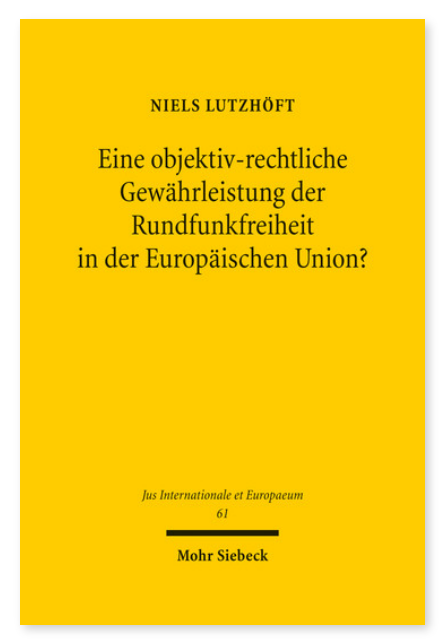

2012. XX, 370 Seiten. JusIntEu 61

ISBN 978-3-16-151876-8

DOI 10.1628/978-3-16-151876-8

eBook PDF 119,00€

ISBN 978-3-16-151701-3

Leinen $119,00 €$
Der Rundfunk übernimmt als »Medium und Faktor« der öffentlichen Meinungsbildung eine tragende Rolle. Verfassungsgerichte in Europa betonen, dass ein freier Rundfunk eine der Grundvoraussetzungen des demokratischen Systems darstellt. Um diese zu sichern, werden Freiheiten im Bereich des Rundfunks häufig funktional mit Blick auf dieses Ziel konzipiert. Der Staat muss die Ausübung der Freiheit durch geeignete einfachgesetzliche Ausgestaltung sichern und die Meinungsvielfalt gewährleisten. Die Maßnahmen, mit denen er dies tut, greifen potenziell in die Dienstleistungsfreiheit ein oder stellen rechtfertigungsbedürftige Beihilfen dar. Niels Lutzhöft löst solche diagonalen Kollisionen mittels eines grundrechtlichen Ansatzes unmittelbar auf EU-Ebene auf und macht die Besonderheiten des Rundfunks unionsrechtlich greifbar. Ein objektiv-rechtlicher Schutz der Rundfunkfreiheit im Unionsrecht balanciert die abwehrrechtlich ausgerichteten Tatbestände auf der Ebene der EU-Verträge aus und verschafft der kulturellen Aufgabe des Rundfunks als negativer Grenze einen unionsrechtlichen Achtungsanspruch.

Niels Lutzhöft Geboren 1975; 2004 Studium der Journalistik an den Universitäten Dortmund und Bordeaux; Studium der Rechtswissenschaft in Bochum und an der Columbia Law School, New York; 2011 Promotion zum Dr. iur., seit 2009 Rechtsanwalt in München.
Jetzt bestellen:

https://mohrsiebeck.com/buch/eine-objektiv-rechtliche-gewaehrleistung-der-rundfunkfreiheit-in-der-europaeischen-union9783161518768?no_cache $=1$

order@mohrsiebeck.com

Telefon: +49 (0)7071-923-17

Telefax: +49 (0)7071-51104 